\title{
Anicteric Leptospirosis-Associated Meningitis in a Tropical Urban Environment, Brazil
}

\author{
Scott A. Nabity, Guilherme C. Araújo, José E. Hagan, Alcinéia O. Damião, \\ Mitermayer G. Reis, Albert I. Ko, Guilherme S. Ribeiro
}

While studying aseptic meningitis in Salvador, Brazil, we diagnosed anicteric leptospirosis in $1.7 \%(5 / 295)$ of patients hospitalized for aseptic meningitis. Leptospirosis-associated meningitis patients had lower mean cerebrospinal fluid cell counts and protein than othercause aseptic meningitis $(p<0.05)$. Clinicians must consider leptospirosis-associated meningitis in appropriate clinical-epidemiologic contexts.

$\mathrm{T}$ The clinical signs of leptospirosis can vary widely, which complicates timely diagnosis and targeted therapy. Aseptic meningitis associated with Leptospi$r a$ infection, hereafter termed leptospirosis-associated meningitis (LAM), has been well described (1-3). However, clinicians diagnose atypical forms of leptospirosis less frequently, particularly in the absence of classic signs (i.e., renal insufficiency or hepatitis). Detection requires a high level of clinical suspicion, and even then imperfect diagnostics for leptospirosis limit timely confirmation.

Leptospirosis causes $\approx 1$ million illnesses annually; this figure does not include LAM (4). Despite the high global burden of leptospirosis and early knowledge that anicteric LAM is underappreciated (1), few existing studies delineate the proportion of aseptic meningitis caused by Leptospira sp. infection in settings in which it is endemic. We performed surveillance for aseptic meningitis in an area of high transmission of urban leptospirosis. Hospital Couto Maia, the Oswaldo Cruz Foundation, and Yale University provided ethics approval for this study.

Author affiliations: Massachusetts General Hospital, Boston, Massachusetts, USA (S.A. Nabity); Instituto Gonçalo Moniz, Salvador, Brazil (G.C. Araújo, A.O. Damião, M.G. Reis, A.I. Ko, G.S. Ribeiro); Yale University, New Haven, Connecticut, USA (J.E. Hagan, M.G. Reis, A.I. Ko); Universidade Federal da Bahia, Salvador, Brazil (M.G. Reis, G.S. Ribeiro)

DOI: https://doi.org/10.3201/eid2609.191001

\section{The Study}

We conducted the study at a public referral hospital for infectious diseases in Salvador, Brazil, April 18-October 18, 2012, during a period of seasonal increased risk for severe leptospirosis such as Weil's disease (5) and severe pulmonary hemorrhagic syndrome (6). We enrolled consecutive patients $\geq 5$ years of age who had a diagnosis of aseptic meningitis, defined by clinical meningitis (fever with severe headache or meningismus); nonturbid, nonpurulent cerebrospinal fluid (CSF) containing 10-2,000 cells $/ \mathrm{m}^{3}$, protein $\leq 150 \mathrm{mg} / \mathrm{dL}$, glucose $\geq 40 \mathrm{mg} / \mathrm{dL}$; and negative results for bacterial meningitis on Gram stain, culture isolation, and latex agglutination tests. From the patients with aseptic meningitis, we aimed to select those most likely to elicit clinical suspicion for leptospirosis; a selection requirement was $\geq 1$ epidemiologic risk factor for classic leptospirosis in the 30 days before symptom onset for leptospirosis testing. Risk factors were contact with floodwater, sewer water, or mud; rats at home or work; and residence or employment in a high-risk environment (i.e., slum community or animal farm) (7). We confirmed LAM by either Leptospira blood culture on EMJH media using $150 \mu \mathrm{L}$ inoculum, or by reactive microagglutination test (MAT) by $\geq 1$ of the following criteria: $\geq 4$-fold acute-convalescent titer rise; seroconversion (undetectable acute-phase titer and convalescent-phase titer $\geq 1: 200$ ); or sample titer $\geq 1: 800$.

The public hospital received regional referrals for lumbar puncture and CSF analysis for suspected meningitis as standard practice; CSF showing $>10$ cells/ $\mathrm{mm}^{3}$ required inpatient observation. At enrollment, we obtained demographic, epidemiologic, and clinical data from patients. We followed the patients during hospitalization to ascertain outcomes. We compared clinical characteristics between leptospirosis-confirmed and unconfirmed patients $\geq 15$ years of age to avoid age confounding. Comparisons were made using Fisher exact test (2-tailed, $\alpha=0.05)$ and Wilcoxon rank-sum test (2-tailed exact, $\alpha=0.05)$. 
We identified 295 patients with aseptic meningitis $\geq 5$ years of age at admission. Of these, $22(7.5 \%)$ had $\geq 1$ epidemiologic risk factor for classic leptospirosis and therefore met criteria for leptospirosis diagnostic testing. Five $(23 \%, 95 \%$ CI $7 \%-44 \%)$ of the 22 had confirmed LAM. Among all 295 patients, noting that 22 of these were tested for leptospirosis, the proportion LAM-confirmed was $1.7 \%$ (95\% CI $0.5 \%-3.9 \%$ ). MAT titers were highest against $L$. interrogans serogroup Canicola for 2 patients and L. interrogans serogroup Icterohaemorrhagiae for 2 others with paired serum specimens (Table 1, https://wwwnc.cdc.gov/ EID/article/26/9/19-1001-T1.htm). A fifth patient confirmed by an acute titer $\geq 1: 800$ had mixed highest titers against $L$. interrogans serogroup Icterohaemorrhagiae and L. kirschineri serogroup Cynopteri. None had a positive hemoculture for Leptospira, and none had clinical jaundice, which we defined as anicteric.

No patient was suspected to have leptospirosis at initial evaluation. However, 1 (patient 3) was subsequently suspected to have leptospirosis within 24 hours of hospitalization when a successive clinician noted mild respiratory distress with bilateral infiltrates on chest radiograph. Three confirmed patients ultimately had antimicrobial drug treatment (Table 1); none required admission to the intensive care unit or died, and all left the hospital at neurologic baseline. LAM patients had lower CSF cell counts and protein than patients with meningitis from other causes (Table 2).

\section{Conclusions}

The overall frequency of anicteric LAM among aseptic meningitis patients appeared low, despite being measured during Salvador's highest rainfall season. We increased diagnostic yield to $23 \%$ with elementary risk stratification for classic leptospirosis. Because this process was likely to miss LAM that did not meet our inclusion criteria for testing, we probably underestimated the true frequency of LAM.

Lower cell counts and CSF protein levels distinguished LAM from other causes of aseptic meningitis, although the small sample size of our study limits their reliability. CSF pleiocytosis accompanies most cases of leptospirosis, particularly during the secondary immune phase of classic disease (2,3), even without clinical meningeal signs. Although typical CSF chemistries for LAM are well known (i.e., slightly elevated cell count and protein; normal-low glucose) (2,3), only 1 previous report showed direct comparison between the CSF of anicteric LAM and nonleptospirosis aseptic meningitis (8). However, the report did not include epidemiologic information and the CSF data were presented in a way that limited statistical comparison.

Two of 5 cases of LAM had the highest MAT titer against serogroup Canicola, which is associated with canine reservoirs (9). Serogroup Icterohaemorrhagiae predominates for classic leptospirosis in this setting $(\approx 90 \%)$ and is typically associated with rat (Rattus norvegicus) reservoirs (5). Thus, our findings suggest that

\begin{tabular}{|c|c|c|c|c|c|}
\hline \multirow[b]{2}{*}{ Characteristic } & \multicolumn{2}{|c|}{$\begin{array}{c}\text { Confirmed leptospirosis-associated } \\
\text { meningitis }\end{array}$} & \multicolumn{3}{|c|}{ Nonleptospirosis aseptic meningitis } \\
\hline & $\begin{array}{c}\text { No. } \\
\text { patients }\end{array}$ & $\begin{array}{c}\text { No. }(\%) \text { or mean } \pm \text { SD } \\
\text { (range) }\end{array}$ & $\begin{array}{c}\text { No. } \\
\text { patients }\end{array}$ & $\begin{array}{c}\text { No. }(\%) \text { or mean } \pm \text { SD } \\
\text { (range) }\end{array}$ & $\mathrm{p}$ value \\
\hline Age, y & 5 & $30.8 \pm 9.9(18-42)$ & 13 & $28.6 \pm 13.4(16-51)$ & $0.746 \ddagger$ \\
\hline No. days of symptoms before hospital care & 5 & $6.4 \pm 1.8(2-8)$ & 13 & $6.2 \pm 5.3(2-20)$ & $0.922 \ddagger$ \\
\hline \multicolumn{6}{|l|}{ Symptom profile§ } \\
\hline Emesis & 5 & $4(80.0)$ & 13 & $8(61.5)$ & 0.615 \\
\hline Photophobia & 5 & $1(20.0)$ & 13 & 0 & 0.278 \\
\hline Nuchal rigidity & 5 & $1(20.0)$ & 13 & $5(38.5)$ & 0.615 \\
\hline Abdominal pain & 5 & $2(40.0)$ & 13 & $2(15.4)$ & 0.533 \\
\hline Diarrhea & 5 & $2(40.0)$ & 13 & $2(15.4)$ & 0.533 \\
\hline Myalgia/arthralgia & 5 & $4(80.0)$ & 13 & $6(46.2)$ & 0.314 \\
\hline Total peripheral eukocytes, $10^{3} / \mathrm{mL}$ & 5 & $9.8 \pm 4.2(4.9-15.5)$ & 13 & $9.2 \pm 1.2(5.2-20.4)$ & $0.800 \ddagger$ \\
\hline Platelets, $10^{3} / \mu \mathrm{L}$ & 5 & $214.8 \pm 98.6(108-336)$ & 13 & $262.8 \pm 52.6(178-350)$ & $0.193 \ddagger$ \\
\hline \multicolumn{6}{|l|}{ Plasma chemistries } \\
\hline Potassium, meq/L & 4 & $4.5 \pm 0.5(4.1-5.2)$ & 11 & $4.3 \pm 0.5(3.6-5.2)$ & $0.504 \ddagger$ \\
\hline Creatinine, $\mathrm{mg} / \mathrm{dL}$ & 5 & $1.1 \pm 0.5(0.6-1.8)$ & 12 & $1.1 \pm 0.3(0.5-1.6)$ & $0.910 \ddagger$ \\
\hline $\mathrm{ALT}, \mathrm{U} / \mathrm{L}$ & 4 & $42.8 \pm 23.0(25-76)$ & 10 & $33.6 \pm 9.5(12-49)$ & $0.297 \ddagger$ \\
\hline \multicolumn{6}{|l|}{ Cerebrospinal fluid profile } \\
\hline Nucleated cells, $10^{6} / \mathrm{L}$ & 5 & $67.6 \pm 48.2(28-150)$ & 13 & $351.3 \pm 402.6(17-1500)$ & $0.025 \pi$ \\
\hline Glucose, mg/dL & 4 & $61.0 \pm 13.7(46-77) \#$ & 12 & $60.9 \pm 11.6(44-84)$ & $0.991 \ddagger$ \\
\hline Protein, $\mathrm{g} / \mathrm{L}$ & 5 & $35.4 \pm 8.8(23-46)$ & 12 & $66.3 \pm 31.3(34-141)$ & $0.014 \pi$ \\
\hline
\end{tabular}

${ }^{*} \mathrm{ALT}$, alanine aminotransferase.

†Analysis restricted to patients $\geq 15$ y of age to avoid confounding of biochemical parameters by age.

$\ddagger 2$-sample $t$-test using pooled variance.

$\S$ All patients had severe headache and none had a seizure.

TWilcoxon sum-rank nonparametric test.

\#Excludes 1 patient with type 2 diabetes who had a blood glucose of 298 and a cerebrospinal fluid glucose of 143. 
there may be notable differences in the epidemiology of LAM and of classic leptospirosis as well as differential pathogenic mechanisms among these serogroups (10). Various serogroups have been implicated in anicteric LAM; they include Icterohaemorrhagiae $(8,11-13)$ and Canicola $(11,12,14)$ from differing epidemiologic settings over time.

We selected our screening criteria to affirm leptospirosis risk based on our epidemiologic understanding of classical leptospirosis. Criteria less grounded in classical leptospirosis risk exposures in this setting (e.g., including exposure to dogs), may help stratify aseptic meningitis patients for diagnostic testing. Similarly, CSF analysis alone is unlikely to properly identify candidates for leptospirosis diagnostic investigation. We did not culture CSF for Leptospira, nor could we attempt PCR on CSF; these limitations may have reduced diagnostic yield.

We ascertained leptospirosis as the cause of meningitis in a setting of high endemic transmission of urban leptospirosis, where severe disease forms are a predominant clinical presentation, but little information has been obtained for aseptic meningitis. Our findings support the development and validation of risk stratification strategies for systematic assessments of aseptic meningitis aiming to detect LAM in regions in which leptospirosis occurs endemically or epidemically. Such strategies, perhaps expanded to include nonrodent animal exposures, would not only help to guide diagnostic work-up but may also direct early introduction of antimicrobial drugs in settings without laboratories capable of diagnosing leptospirosis. Until there is an effective approach to differentiate anicteric LAM from other-cause aseptic meningitis at clinical presentation in low-resource environments, clinicians must maintain a robust and enduring index of suspicion for leptospirosis when evaluating patients with aseptic meningitis.

\section{Acknowledgments}

We thank the staff of Couto Maia Hospital in Salvador, notably Ronaldo Ribeiro, Ana Veronica Mascarenhas, and Ceuci Nunes, for their collaboration. We also thank Nivison Nery and Renan Rosa for assistance with data curation, Jaqueline Cruz for diagnostic laboratory work, and the patients who consented to participate.

This work was supported by the National Institutes of Health (grant nos. R44 AI072856, U01 AI088752, R01 AI121207, D43 TW00919), the Fogarty International Clinical Research Scholars Program, the Duke Global Health Institute, and the Brazilian National Council for Scientific and Technological Development (CNPq). The funders had no role in study design, data collection and analysis, decision to publish, or preparation of the manuscript. M.G.R. and G.S.R. had scholarships from CNPq.

\section{About the Author}

Dr. Nabity is a medical epidemiologist who at the time of this study was with Massachusetts General Hospital, Boston, Massachusetts. His research involves the prevention, control, and elimination of infectious diseases.

\section{References}

1. Walch-Sorgdrager B. Leptospiroses. Bull Heal Organ (League Nations). 1939;8:143-386.

2. Coyle PK, Dattwyler R. Spirochetal infection of the central nervous system. Infect Dis Clin North Am. 1990;4:731-46.

3. Farr RW. Leptospirosis. Clin Infect Dis. 1995;21:1-8. https://doi.org/10.1093/clinids/21.1.1

4. Costa F, Hagan JE, Calcagno J, Kane M, Torgerson P, Martinez-Silveira MS, et al. Global morbidity and mortality of leptospirosis: a systematic review. PLoS Negl Trop Dis. 2015;9:e0003898. https:// doi.org/10.1371/ journal.pntd.0003898

5. Ko AI, Galvão MG, Ribeiro CMD, Johnson WD Jr, Riley LW; Salvador Leptospirosis Study Group. Urban epidemic of severe leptospirosis in Brazil. Lancet. 1999;354:820-5. https://doi.org/10.1016/S0140-6736(99)80012-9

6. Gouveia EL, Metcalfe J, de Carvalho AL, Aires TS, Villasboas-Bisneto JC, Queirroz A, et al. Leptospirosisassociated severe pulmonary hemorrhagic syndrome, Salvador, Brazil. Emerg Infect Dis. 2008;14:505-8. https://doi.org/10.3201/eid1403.071064

7. Nabity SA, Hagan JE, Araújo G, Damião AO, Cruz JS, Nery N, et al. Prospective evaluation of accuracy and clinical utility of the Dual Path Platform (DPP) assay for the point-ofcare diagnosis of leptospirosis in hospitalized patients. PLoS Negl Trop Dis. 2018;12:e0006285. https:// doi.org/10.1371/ journal.pntd.0006285

8. Costa E, Costa Y, Santos RR, Silva HR, Silva NG, Silva IC, et al. Leptospirosis: a cause of aseptic meningitis [in Portuguese]. Rev Med Bahia. 1977;23:107-18.

9. Bharti AR, Nally JE, Ricaldi JN, Matthias MA, Diaz MM, Lovett MA, et al.; Peru-United States Leptospirosis Consortium. Leptospirosis: a zoonotic disease of global importance. Lancet Infect Dis. 2003;3:757-71. https:/ / doi.org/10.1016/S1473-3099(03)00830-2

10. Ko AI, Goarant C, Picardeau M. Leptospira: the dawn of the molecular genetics era for an emerging zoonotic pathogen. Nat Rev Microbiol. 2009;7:736-47. https:// doi.org/10.1038/ nrmicro2208

11. Beeson PB, Hankey DD. Leptospiral meningitis. AMA Arch Intern Med. 1952;89:575-83. https:/ / doi.org/10.1001/ archinte.1952.00240040054007

12. Galvão PAA, Scheinberg MA, Pereira Jr W, Fucs M, Sonnewend JPAS, Farhat CK, et al. Leptospirosis of childhood [in Portuguese]. Pediatr Prat. 1968;39:155-160.

13. Amato Neto V, de Avila CA, Kawarabayashi M. Leptospira meningitis: cases reported in the city of São Paulo, during an epidemic outbreak of meningococcal disease [in Portuguese]. Rev Inst Med Trop Sao Paulo. 1982;24:322-5.

14. Hubbert WT. Leptospirosis in California. Public Health Rep. 1967;82:429-33. https://doi.org/10.2307/4593034

Address for correspondence: Guilherme Sousa Ribeiro, Instituto Gonçalo Moniz, Fundação Oswaldo Cruz, Rua Waldemar Falcão, 121, Candeal, 40296-710, Salvador, Bahia, Brazil; email: guilherme.ribeiro@fiocruz.br 